similar law (presented by Hon. L. F. Johnson of Franklin County). I hope that a similar law will be enacted in all the states. If we were to do our duty, we would need no law to protect us and our patients whose lives are put in our keeping, and we should not under any conditions or circumstances preseribe a medicine that we were not absolutely familiar with.

I trust that the members of this society will join with me in resolving to use in the future only those drugs from which we can reasonably expect results, and, if possible, to have all remedies compounded by our own druggists. We should also notify the druggists that we shall accept only pure chemicals, such as those made by reputable firms. It is not our province altogether to find only palatable drugs. Let the homeopath have a monopoly along this line if he will; that which we most desire is results. Occasionally a medicine that is pleasant to the taste can have little or no therapeutic value, except for its mental effect on some of our most unfortunate cases. That we will appeal to the intellect rather than to the superstition, prejudice and ignorance.

I see each succeeding day signs of better things and that there is room for improvement no one can doubt, since it is estimated that over $\$ 100,000,000$ has been expended annually for patent and proprietary nostrums. No wonder is it that legislatures are slow to enact laws to modify the sale of these "patents"; no wonder it is that the manufacturers of these miserable compounds are on the run, because at least $\$ 75,000,000$ of this money must be profit, and if there is any one thing that will invite a keener interest than another it is the probable loss of money.

Then think what so vast a sum as this could and would do in influencing legislation that would be detrimental to this nefarious business. The manufacturers use every device known to the professional pirate and plunderer, such. as threatening newspapers with loss of their advertising and appealing to retail druggists to help protect their property rights. These vendors want and demand our closest secrecy in protecting their rights, as they say. Afraid even to let the uneducated class of their countrymen know what they have been swallowing for all these years and for what they have paid so many honest dollars, notwithstanding the fact that these manufacturers know that the users of their medicines are, of all people, most gullible! I have seen it estimated that 75 per cent. of all the prescriptions that are written by the medical profession of this country call for proprietaries whose formulas are known and proprietaries whose formulas are secret, about one-half each. Is this not a shame when we know that many of the so-called proprietaries are no better than the rankest of the patents?

Let us see to it that we have a druggist prepare our prescriptions who is competent so to do; that we demand of him a square deal and only the purest medicines that can be had, asking no quarter from any source and showing none, save when compatible with the highest sense of duty to our patients and to ourselves, and lend our assistance in this campaign of education wherever and whenever we can be of service. Thus the people with whom we live and practice our art will have a higher regard for our ability and fidelity.

Corpora Aranti.-These structures in the brain are named after Giulio Cesare Aranzio (English, Aranzi; Latin, Aran. tius), an Italian anatomist, born at Bologna in 1530, died in 1589, according to the Medical Book News. He was professor of anatomy for thirty-two years in the university at Bologna, and physician to Pope Gregory XIII.

\section{FOUR POINTS OF INILEREST IN MAJOR ANESTHESIA.}

ROBERT H. M. DAWBARN, M.D.

Professor of Surgery, New York Polyclinic Medical School and Hospital. Surgeon to the City Hospital. NEW YORK CITY.

The first of these points on anesthesia has to do with the use of ethyl chlorid prior to the administration of ether. Since the safety of this very pleasant method has been demonstrated it has rapidly grown in popularity. Dr. V. C. Pedersen, anesthetist to Roosevelt Hospital, has informed me that, unless otherwise directed by the surgeon, this is now always his preference instead of beginning the anesthesia with liquid laughing-gas.

Six months ago a certain New York firm informed me that hereafter they intended to manufacture their own ethyl chlorid instead of importing it; and, through their representative, asked my advice as to the best size of tube to supply. After som experimenting $I$ advised

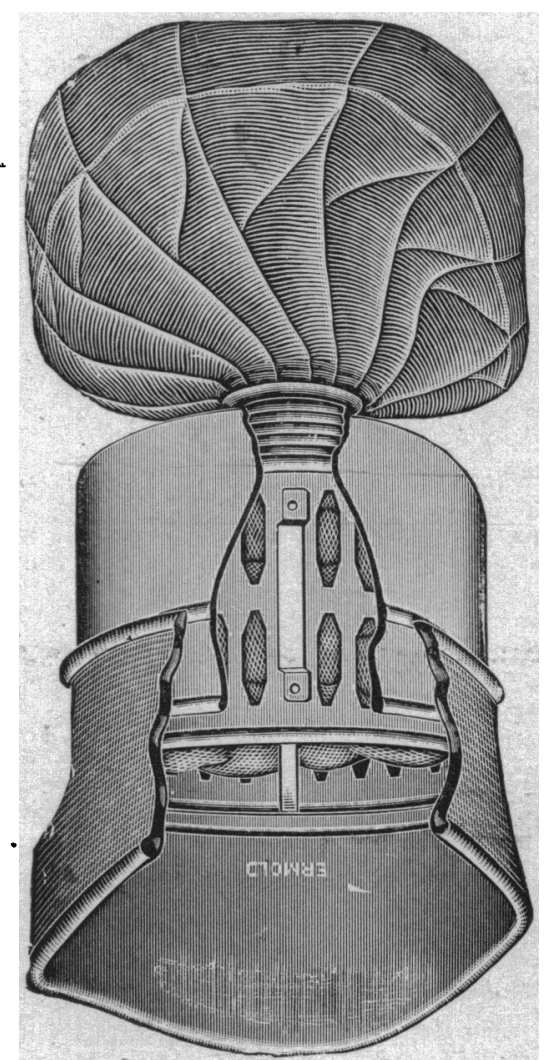

The inhaler. This illustration does not show the relative size of the thin rubber air-bag, which is large enough for the tidal air of the largest man.

a 5 c.c. tube. This is drawn to a fine point at one end, easily broken off and sealed by a blowpipe flame.

I also recommend the following method of usage: Assuming that the Clover air-bag principle of ether inhaler is the one to be used (the simple and cheap form known by my name and used for nearly 15 years at the City Hospital has never yet been followed by ether pneumonia), two or three of the 5 c.c. tubes of ethyl chlorid are wrapped each in an opened gauze sponge, with an elastic snapped about this jacket, and are then dropped within the air-bag. With the face-piece in position, the tip of one of these tubes is brokenthrough the rubber bag-and the anesthesia is at once commenced. Thus there is no waste, and the gauze wrapper prevents cutting the air-bag during breakage. If instead the tube be broken outside the bag and then 
dropped within it, so rapid is the escape of this most volatile liquid that one is fortunate to secure the services of half the tube's contents.

If need be, the second and third tubes can be broken too. As soon as the patient is thoroughly asleep the ether-cage is slipped home in the face-piece, and gradually the ether anesthesia replaces that from the ethyl chlorid where a long operation is required.

Of course, where much more complicated and expensive ether inhalers are to be used, this tube of Squibb's is not indicated; and instead a spray of ethyl chlorid is directed into an opening in the inhaler for the purpose, from a large container. At present, however, we are assuming that the simpler kind of apparatus-which is presumably in use by a large majority of practitioners - is to be used. Chilling the lungs by ether continually poured on and using a towel-and-newspaper cone, or an Allis inhaler, is so obviously the chief cause of ether pneumonia that it would seem that the rebreathed, lung-warmed ether of the Clover air-bag principle should by to-day have commended itself to all members of the profession. If there be still some who differ, however, it may be worth while to add that all the experts in anesthesia in New York-I mean the men who do nothing else-are agreed on this point. This method also results in a great saving in ether, and the patient recovers more certainly and sooner, being far less saturated with the drug.

2. The second point to be mentioned is a means of preventing trouble from chloroform when this is used at night in presence of a naked flame in the room. Experience has shown that before the end of a long operation the surgeon and his assistants will be coughing in consequence of the chloroform becoming decomposed and giving off nascent chlorin. About fifteen years ago -perhaps more-it occurred to me to try hanging, not far from the lamp or gas jets, handkerchiefs dipped in ammonia. The resultant chemical affinity at once produces ammonium chlorid and prevents the cause of the coughing. Recently I mentioned this to Dr. Thomas L. Bennett, perhaps the best known of the men doing exclusively anesthesia work here, and he said he had never before heard of it. As I have not found it mentioned in a rather hasty review of text-books, I assume that at least this plan ought to be more widely known.

3 . 'The third suggestion of this paper is far from original, but how forgotten it is in practice!. I refer to giving the anesthetic during the natural sleep. In all possible instances of major operating during the earliest years let us select an hour which is regularly that of the child's daily sleep, and, entering the darkened room noisclessly, let us anesthetize so cautiously and gradually-using chloroform mask held far from the face, employing the drop method and being in no hurry-that the little sleeper only awakens when the operation is ended!

It makes an astonishing difference in the amount of chloroform required whether this safest of plans (and most neglected) is used, or whether instead the frightened child is awake, struggling and screaming. Also, be it remembered, it earns the mother's gratitude.

Although easy of accomplishment with chloroform and in childhood, during natural sleep, such anesthesia, using ether, is far more difficult, almost impossible indeed, and rarely can be done on adults at all.

4. The fourth and last of the four small points I wished to bring out-if, indeed, anything is small that makes at all for the patient's comfort or safet $y$-is in reference to the advice which. without exception, one sees included in the instructions to the voung anes- thetist; namely, always to remove from the patient's mouth any plate containing artificial teeth.

In my opinion, there are exceptions to this, and the physician should be entitled to use his judgment. Obviously the plate should be removed when it is so small that, if dislodged, it might prove dangerous either by being swallowed or lodged in the gullet. In many instances, however, the patient is wearing a complete or nearly complete set or sets and possesses only an ordinary size of pharynx. In such cases, swallowing or choking on the plate is out of the question; and when it is taken out the cheeks and lips so fall in as to encroach, in some patients, to a serious degree on the breathing space within the mouth. This is worth remembering, especially when there chances to be much nasal obstruction, which is far from rare.

In a recent conversation with Dr. James T. Gwathmey, anesthetist to the City Hospital, I was pleased to observe that on this point he holds the same views.

\section{ACCURACY IN DIETETICS.*}

DUDLEY ROBERTS, M.D.

Associating Visiting I'hysician, Brooklyn Hospital. BROOKLYN.

The general trend toward accuracy in many departments of medicine serves to emphasize the prevalent disregard for a similar advance in dietetics. The importance of carefully selecting the articles of food for certain cases is very generally urged, but not as commonly practiced. Although it would seem to be a subject of equal importance, but little stress is ever laid on the necessity of regulating the amount of food to fit the exact known demands of a particular individual. That the demands and hence the supply of food should vary with the weight, shape of the body, age and condition of activity has been too well proved to permit of question.

We can only account for the prevalent neglect of this factor in dietetic ordering by supposing that the matter has never been presented in practicable form. It is essential that the number of nutrients in a given food substance be quickly determined and that the patient receive instructions as to the amount of food in such terms as can be readily comprehended by the average invalid or nurse. Food weighing must be discarded, as it certainly can not be carried out in the ordinary household, public eating place or even in the average institution. Unquestionably we must consider not what is served, but rather what is actually eaten; otherwise one may be misled into making serious errors.

Fortunately the number of simple foods, the value of which it is necessary to know in order to prescribe a dietary to the class of cases that should have definite diet lists, is comparatively small; from these simple foods one can readily calculate the value of such compound foods as are ordinarily used in these diets. In the accompanying Table 1 the most convenient unit of household measure has been taken and the food value of its content of food in the state in which it is eaten has been calculated; the value of the various articles in the raw state has been taken from the works of Atwater, Ruebner, Chittenden, Hutchinson and others. While these units may not at any time be exact, in a number of meals the deficiencies and excesses balance.

It is not contended that more than a small minority of patients need to be put on regular diet lists; very

* Read before the Medical Section of the Kings County Medical Society.

1. The author, on request, will furnish these tables of food supply and demands on a card of rest pocket size. 